\title{
Male, Self-Report
}

National Cancer Institute

\section{Source}

National Cancer Institute. Male, Self-Report. NCI Thesaurus. Code C46107.

An individual who reports to be male, the sex that ordinarily produces sperm. 